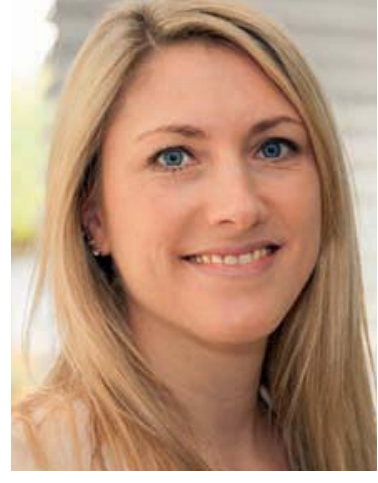

Simone Gritsch

Inhaltliche Leitung ergopraxis

simone.gritsch@thieme.de

\title{
Klienten fragen
}

Mit Beginn unserer beruflichen Laufbahn beschäftigt uns die Frage: Was ist eigentlich Ergotherapie? In der Hoffnung, dass Kompliziertes möglichst fachlich klingt, versuchen die einen, die Antwort hochwissenschaftlich zu formulieren. Andere nutzen ganz praktische Beispiele aus ihrer täglichen Arbeit. Wieder andere werden kreativ und antworten zum Beispiel mit einer Gegenfrage oder plakativen Statements. Es gibt viele Varianten, und doch "flutscht" es bei keiner so richtig. Darum würde ich den Spieß heute gerne umdrehen: Was halten Sie davon, wenn wir diese Frage einfach mal an unsere Klienten richten? Wir sind ja schließlich klientenzentriert.

Fühlen Sie sich also hiermit aufgerufen, bei Ihren Klienten nachzuhören, was Ergotherapie für sie bedeutet, und lassen Sie Ihrer (gemeinsamen) Kreativität freien Lauf: Wortspiele, Zeichnungen, Gedichte, Skulpturen, Fotos oder Videos. Was auch immer dabei herauskommen mag, wir freuen uns über Ihre Antworten per E-Mail an Simone.Gritsch@thieme.de oder per Post an Georg Thieme Verlag, Redaktion ergopraxis, Rüdigerstraße 14, 70469 Stuttgart. Einsendeschluss ist der 31. August 2016. Die überzeugendsten Antworten bekommen selbstverständlich einen Ehrenplatz in ergopraxis und ein Thieme-Ergo-Überraschungspaket.

Herzliche Grüße und einen kreativen Sommer Ihre

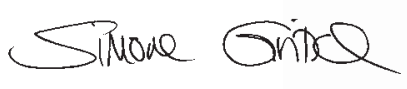

